\title{
Giorgio Armani Corporate Management Profile Analysis
}

\author{
Xue,Di-Fan ${ }^{1, a}$ \\ ${ }^{1}$ Department of Tourism management, Shanghai sanda University, Pudong District, shanghai, China \\ a2876601419@qq.com
}

\begin{abstract}
The pattern of the fashion industry worldwide today is in fact a fashion circle centered on international cities such as Paris, Milan, New York and London, each of which is home to multitudinous famous fashion brands. Even though China, as the world's largest apparel producer, consumer and exporter, boasts many local brands, it owns very few worldrenowned ones. Therefore, this paper takes top name brand Giorgio Armani as the research object and analyze its categories, store layout and merchandise array, brand advertising and sales system operation, job recruitment and training, and brand asset and strategy, so as to provide suggestions for the future development of China's fashion industry. This paper adopts the field research method to analyze the above aspects of Giorgio Armani by visiting different stores in Shanghai.
\end{abstract}

Keywords: Armani, Business Management, Fashion Industry

\section{阿玛尼企业管理概况分析}

薛迪凡 $1, \mathrm{a}$

1 上海杉达学院旅游管理系, 浦东新区, 上海, 中国

a2876601419@qq.com

\section{摘要}

当今世界时尚产业的格局, 是以巴黎、米兰、纽约、伦敦等国际都市为中心的时尚圈层, 每个城市都有着众多 知名时尚品牌。然而作为世界最大的服装生产, 消费和出口大国, 中国虽有众多本土品牌, 却鲜有国际知名品 牌。为此, 本文以国际时尚品牌阿玛尼为研究对象, 主要从阿玛尼企业的品类、门店布置和商品成列层次,阿 玛尼企业的品牌广告和销售系统运营,阿玛尼企业岗位招聘和岗位培训，阿玛尼企业品牌资产和战略等几个方 面进行分析。进而为我国时装产业的发展提出建议。本文采用实地调研法，对上海的不同门店进行了走访并分 析。

关键词：阿玛尼 企业管理 时装产业

\section{1. 阿玛尼企业的品类、门店布置和商品成列层 次}

\section{1. 阿玛尼企业的品类}

从服装市场来讲, 奢侈品每年的高定、时装周, 都会成为这一年时装圈的风向标。近年轻奢的概念也 被提出。为了迎合不同消费者的知晓、喜爱和尊重, 阿玛尼对针对不同的消费者群体也进行细分。产品品 类主要有: 男装、女装、运动装、体育用品、牛仔装、 皮饰品、配件、香水、家居饰品。公司除经营服装外，
还设计领带、眼镜、丝巾、皮革用品、香水乃至家居 用品等, 产品销往全球 100 多个国家和地区。

\section{2. 主副线的门店布置和商品成列层次}

\subsection{1. 阿玛尼门店选址}

阿玛尼在选择商店位置的时候, 通常选择大型和 高端购物中心一楼。商店面积通常约为 150 平方米, 阿玛尼始终秉承品牌理念, 保持统一的装饰风格。店 面装饰一般以白色, 黑色和米色为主要色彩, 针对的 客户群不同，能带给消费者简洁、自由或优雅的不同 
感受。商店中的灯光主要使用可调节角度的暖色小灯, 这种色调为顾客营造了一种亲切而舒适的氛围。

\subsection{2. 阿玛尼企业主副商品成列层次}

\section{GIORGIO ARMANI 即阿玛尼主线}

Giorgio Armani 专攻高级成衣, 包含男女装。它 是阿玛尼最经典的成衣和正装系列, 也是阿玛尼所有 营销活动中最具价值的经典产品。产品用料考究, 价 格在 1 万元以上，目标消费群体在 30-50 岁之间，主 要是富裕阶层。也是拥有副线最多的主品牌。最能体 现阿玛尼“随意优雅”特色。Giorgio Armani 是高级成 衣的品牌线, 针对客户群也是高端商务人士, 年龄大 约在 30 岁朝上。位于上海恒隆广场的 Giorgio Armani, 桭窗内两套当季新品成衣是灰黑色调, 所以展台板也 采用同色调的灰蓝色, 与门框米色搭配, 给人呈现出 一种低调奢华的感觉。店内整体采用悬挂陈列方式, 围绕中间柱子呈圆形展开, 这种方式有助于顾客站在 中间就能全方位地欣赏到商品, 最简单平淡的陈列方 式正契合 Armani 低调奢华的追求。

\section{EMPORIO ARMANI 即阿玛尼年轻副线}

Emporio Armani 是阿玛尼年轻系列, 走轻奢路线。 虽然是副线，但经历多年发展后逐渐成为可以独挡一 面的大牌, 并且发展了属于自己的副线品牌。是阿玛 尼旗下重要的支线品牌, 货品种类有 Emporio Armani 男装、女装、鞋履、香水、阿玛尼眼镜饰物等, 在整 个集团收入中几乎与主线 Giorgio Armani 持平, 每年 都会参加米兰时装周。价格普遍在 2500-15000。位于 上海久光百货的 Emporio Armani 从店面装潢上就能 看出明显的定位上的区别, 由于针对的客户人群是年 轻人, 所以在店面样貌上看上去没有 Giorgio Armani 沉稳。店铺还是采用了经典三色, 米色占比最多, 显 得整个店铺更亮更有活力, 但又比其他年轻品牌多了 一丝优雅。其次, 店铺内射灯的数量明显比 Giorgio Armani 多了一倍, 使得整个店铺明亮且富有朝气。采 用关联陈列的方法, 将种类不同但效用方面相互补充 的商品陈列在一起, 以吸引并方便顾客伴随购买。

\section{2. 阿玛尼企业的品牌广告和销售系统运营}

\section{1. 品牌广告}

\section{1. 1. 广告树立形象}

广告是沟通的桥梁。品牌方通过广告传递出形象, 潜移默化在消费者心中树立对产品的认知, 以便促成 日后的消费行为。在诸多奢侈品品牌的竞争中, 如何 凸显品牌形象和个性是一大课题。阿玛尼在中国区的 经营宗旨是, 让中国消费者通过广告大片感受欧洲生 活艺术文化, 体验个性化、高品质的家居产品。其品 牌价值核心词是“个性”、“优雅”、“时尚”。

\subsection{2. 广告的艺术性}

阿玛尼广告的表现形式不仅限于艺术展、时装秀 等露出平台。每年的头部广告大片为春夏季和秋冬季 两部, 头部大片是用来定位本季风格和主推款式的。 而各种代言广告则增加了品牌曝光度, 一方面及时更 新产品让消费者知晓, 另一方面, 阿玛尼会选择与品 牌气质相符的明星, 他们既能带货、又有天然的粉丝 群体买单和有组织的宣传。

\section{2. 销售系统}

\subsection{1. 定价策略}

阿玛尼的产品策略跟随市场的变化而调整, 基于 社会阶层分类。根据每种社会阶层的收入、生活方式、 偏好和价值观等因素, 推出相对应产品, 并给出优惠 措施。阿玛尼集团的品牌策略是金字塔模型, 价格也 由底部的几百到到顶端的几十万不等。

表 1 阿玛尼品牌价格金字塔模型

\begin{tabular}{|l|l|}
\hline 1 & Prive \\
\hline 2 & Giorgio Armani \\
\hline 3 & Armani Collezioni \\
\hline 4 & Emporio Armani, Armani Jeans \\
\hline 5 & A/X Armani Exchange \\
\hline
\end{tabular}

从上表中可以看出，阿玛尼对不同目标消费人群 制定了分段的价格策略。

1 为定制高级时装, 每套价格超过 20 万, 为包括 好莱坞一线明星和皇室成员在内的有限人群服务。

2 为最经典衣和正装系列。衣物用料精良, 价格 高达 1 万元以上, 目标消费群体是 30-50 岁富裕阶层。

3 为 “阿玛尼黑标系列”, 主推高级成衣, 价格 比乔治阿玛尼的产品低 $20 \%$, 适合成功的商人。

4 为现代设计、豪华趋势一般服装, 主要面向中 青年和休闲人群, 价格在 1000 元左右。

5 是阿玛尼产品链上的特许外包和零售品牌。主 要面向大众超市, 以便装为主, 款式简单, 面向大众。

\subsection{2. 促销策略}

促销活动需要运用各种有效的方法来推动信息 传播, 激发顾客的购买欲。对于时尚服装来说, 与价 格促销相比, 比较典型有效的促销策略是通过广告和 公关活动传递信息, 既不会太掉档, 还能做品牌宣传。 阿玛尼每年举办数场时装秀和新品发布会, 可以引导 消费者及时购买最新的服装; 时装秀和时装系列具有 很高的娱乐性和观赏性, 促进品牌宣传的加速。阿玛 尼专卖店几乎没有价格促销活动, 每年只有一些过季 产品会转移到奥特莱斯门店进行打折销售。因此，阿 
玛尼品牌一直在消费者心中保持着良好的品牌形象。

\section{3. 阿玛尼企业岗位招聘和岗位培训}

\section{1. 阿玛尼岗位招聘分析}

在国外，阿玛尼与诸多时尚院校合作，提供大量 实习机会, 帮助时尚学院学生产品研发, 从创建样板 到排料图。在对于阿玛尼上海各门店的实习生招聘简 章研究中发现, 实习满两个月就有机会内推 summer intern 项目，满三个月就有机会内推 MT 项目。招聘 规模由进入中国市场时核心以港澳为主到辐射全国; 招聘职位包含线下门店专柜到线上销售的人员。员工 福利包络: 学习相应品牌的专业培训课程, 正规的五 险一金, 额外商业医疗保险, 定期的公司福利（节假 日福利/员工内买/免费产品）。

\section{2. 阿玛尼员工培训方法}

通过岗位要求的培训, 新员工能够很快胜任岗位, 提高工作效率, 取得较好的工作业绩, 起到事半功倍 的效果。为今后的工作、管理打下了基础。阿玛尼公 司主要从意志培训, 认知培训, 职业培训三个方面对 员工进行训练。

\section{4. 阿玛尼企业品牌资产和战略}

\section{1. 多品牌线塑造品牌资产}

公司目前已经成为紧密型品牌集群, 由二十多个品牌 线共同组成。奢品牌延伸是阿玛尼资产利用的主要方法。阿 玛尼是首个创造出时装行业 “副牌” , 在 90 年代时候开始 实施品牌延伸的策略, 在横向延伸上, 阿玛尼使用授权运行 等手段, 将品牌的范围扩大到很多行业。

\section{2. 通过收购加强控制}

阿玛尼集团会收购给自己贴牌制造的公司和厂 商。但是它收购准则是对别的品牌不收购。一方面, 阿玛尼集团使用资金掌握大多数生产和分销, 另一方 面也有助于通过分销商和厂家对用户的需求进行了 解和掌握, 从而确保品牌风格得以保持。阿玛尼每天 都要对全球各国各区域上报的当天销售数据进行观 察和研究, 从而熟悉市场动态。

\section{3. 加强对零售终端的控制}

大力发展的零售店, 严格地掌控零售端, 也是阿 玛尼的运营和销售的策略。1974 年在意大利创建阿玛 尼品牌, 然后 1989 年拓展到英国伦敦, 1991 年又在 美国开拓一片天地。1998 年阿玛尼将根茎伸展到中国 大陆。集团使用矩阵形式组织结构, 也就是每个经理
要向当地市场和总部对应职责部门的上级管理者汇 报工作内容和销售情况。使总部能严格把控零售终端, 并且很快接收来自各个零售店的信息, 并且及时制作 相应策略和决定。

\section{4. 基于不同客户市场投放不同类型广告}

据艾瑞咨询出具的《2018 年中国 95 后微博营销 洞察报告》显示, 比起价格战, 大部分 95 后微博平 台用户表示在选择商品时更注重商品的外观和时尚, 以及其是否紧跟潮流。由于年轻人对新鲜事物的接受 度更高, 对视频等具象化的形式更加喜爱, 以视频作 为广告形式会产生更好的效果. 阿玛尼更想抓住都市 丽人、美妆用户这一人群，它投放的产品广告，其中 彩妆的力度尤为强力, 如阿玛尼传奇红管/黑管、红/ 黑气垫, 都是新浪微博开屏页的广告常客。

\section{5. 结论}

首先, 阿玛尼历经三十多年的发展, 在时尚领域 占据了很高地位, 拥有非常高的国际认知度。通过发 展多个品牌, 提高了销售额也使品牌资产不断增加。 但不足之处是品牌运营的战线很长、副线种类过多、 知名度的不良影响导致了很多噟品的出现, 这在一定 程度上对品牌的核心价值产生影响。因此, 中国时装 企业在对销售终端进行管理的时候, 要寻找更好的出 路，主动发现当今市场中新的商业价值。

其次, 品牌门店布置和商品成列层次是品牌识别 的其中一种表现形式。中国时装企业如果想迈入高端 消费品和精品品类竞争序列, 视觉体系的建立, 从店 面设计、货品摆放设计、棏窗设计都应该进一步雕玩。 中国时装企业重点都放在网络平台社交媒体的推广, 应用淘宝, 抖音, 快手等 app 做直播售卖和宣传, 靠 人气网红和明星带货, 急需具有艺术审美价值的广告 大片, 以及具有视觉冲击力的时装走秀会。

最后，欧洲老牌奢侈品历史高达上百年，但是阿 玛尼品牌创立时间较短, 没有深厚的文化内涵, 导致 难以登上奢侈品的顶端, 也就是从高端消费品过渡到 奢侈品。从阿玛尼的案例可以看出, 想打造奢牌, 品 牌原产地就是产品的身份标签。如果能对中国本土文 化底蕴和历史价值进行充分挖掘, 加强品质把控, 保 持创新活力, 将有利于促进中国时装企业向高端过渡。

\section{REFERENCES}

[1] HUANG Yi-qun. Taking Hermes as an Example[J]. Study of Luxury Brand Marketing Strategy, 2018(5):2-4.

[2] Kevin Lane Keller, 2003. Strategic Brand Management $[\mathrm{M}]$ translated by LI Nai-he, LI Ling, SHEN Wei, CAO Jing. Beijing: China Renmin University Press. 3-4. 
[3] SU Yong, CHEN Xiao-ping. 2003. A Comprehensive Research on Brands. [M]. Shanghai: Shanghai People's Publishing House, 35 .

[4] CHENG Yu-ning. 2014. Brand Planning and Management[M]. Beijing: China Renmin University Press,208-209.

[5] LI Yuan-kai.2008, A Research on Channel Marketing in Consumer Goods Industry [D]: [M]. Shanghai: Fudan University. 